\title{
Territórios sociais de resistência em comunidades de remanescentes de quilombos
}

\begin{abstract}
Resumo
Este trabalho visa analisar territórios sociais de resistência de comunidades remanescentes de quilombos e os limites desses territórios, construindo a raiz da criação da Agrovila Peru. Essa Agrovila é um território político-jurídico criado pelo Estado brasileiro, para abrigar dez comunidades quilombolas, deslocadas compulsoriamente das terras que ocupavam até 1987, quando a Aeronáutica instala nelas o Centro de Lançamento de Foguetes de Alcântara - CLA - no Maranhão. A partir da pesquisa etnográfica realizada na Comunidade Quilombola Peru, uma das dez comunidades quilombolas que compõem a Agrovila Peru, analisam-se os elementos de identidade cultural reiterados pelos quilombolas, para construir ou desconstruir fronteiras com outro território, 0 território político-jurídico da Agrovila Peru. Nesse sentido, observa-se a flexibilidade das fronteiras desses territórios de resistência, isto é, como eles se compõem e decompõem conforme as posições dos atores sociais no espaço, nas diversas esferas da vida social e cultural: religiosa, ambiental, econômica e política.
\end{abstract}

Palavras-chave: Territórios de resistência. Identidade cultural. Comunidades quilombolas.

\begin{abstract}
This research aims to analyze remnants social territories resistance communities of quilombo, and the bounds of this territory, built from the Agrovila Peru root. This Agrovila is a legal and political territory created by the Brazilian government to house ten maroon communities displaced compulsorily from lands occupied by only them until 1987, when the Aeronautical install in them the Alcântara Rockets Launch Center - ARLC - at Maranhão. From this ethnographic research realized in the Peru Quilombola Communities, in one of the ten maroon communities that composes the Agrovila Peru, are analyzed the cultural identity elements reiterated by maroons to build or destroy bounds with another territory, legal and political territory Agrovila Peru. Thus, is observed the flexibility of this resistance territory bounds, in other words, how they compose and decompose them self-guided by the socials agents in the space, in the many different spheres of the social and cultural life: religious, environmental, economic e political.
\end{abstract}

Keyword: Resistance Territories. Cultural Identity. Maroon Communities.

\footnotetext{
${ }_{1}^{1}$ Pedagoga, mestranda em Ambiente e Desenvolvimento. Centro Universitário Univates. verissima@fest.edu.br
} 


\section{Apresentação}

Como toda categoria, o território tem múltiplos significados, constrói-se a partir de diversas representações dos atores sociais no espaço, seja no âmbito físico, jurídico ou social. E o caminho adotado, para abordar as diversas posições dos atores sociais no espaço, é a análise das identidades, em vista de que, a partir das identidades, podem-se perceber as fronteiras que definem os territórios. Trata-se de territórios construídos e desconstruídos conforme os posicionamentos sociais, tanto dos atores sociais coletivos (instituições) quanto dos individuais (as pessoas).

Nesse sentido, neste artigo, vão se examinar três dimensões de territórios, qualificados de resistência, com base em dados históricos, na observação realizada durante a pesquisa de campo etnográfica e na análise das representações dos quilombolas acerca do processo de deslocamento das comunidades de origem e da posterior ocupação da Agrovila Peru. Mesmo que o território não seja um fenômeno desconectado do social, um espaço definido por elementos meramente físicos, aqui vão ser considerados os componentes físicos e o valor simbólico que eles têm no âmbito da comunidade estudada.

\section{Construção histórica dos territórios de quilombo}

Os territórios sociais de resistência foram construídos pelos africanos escravizados no Brasil desde o período da colonização. Neles, os escravos buscavam o fortalecimento da identidade com atitudes de resistência perante os padrões estabelecidos pela sociedade escravocrata. Portanto, neste cenário histórico e social, os territórios de resistência, identificados como quilombos ${ }^{2}$ pelo Conselho Ultramarino, em 1740, são locais de refúgio dos negros que conseguem escapar da senzala, adentram na mata e ali criam uma forma de viver, a partir da agricultura de subsistência, vivendo sob ataque constante de militares e capitães do mato.

Esta realidade é pensada aqui a partir das singularidades do município de Alcântara $^{3}$, no estado do Maranhão ${ }^{4}$, estado onde o sistema de escravidão foi introduzido pela colonização portuguesa, no século XVII. Neste contexto, os escravos africanos, num primeiro momento, foram usados como mão de obra para produzir e exportar produtos brasileiros, para, depois, tornarem-se mercadoria, negócio lucrativo no tráfico negreiro. "O Maranhão importava em média 2.000 escravos por ano" (VIVEIROS apud BRAGA, 2011, p. 30), mão de obra que lhe permitiu impulsionar o desenvolvimento econômico. O estado passou a ocupar o quarto lugar na exportação de produtos agrícolas do Brasil, tornando Alcântara um "local de produção e proeminência de ricos fazendeiros" (BRAGA, 2011, p. 33).

2 Quilombos: no ano de 1740, o Conselho Ultramarino definia como quilombo todo núcleo que reunisse mais de cinco escravos fugidos, mesmo sem nenhum tipo de edificação (LOPES, 2004, p. 67).

${ }^{3}$ Alcântara - cidade originada de uma aldeia de índios Tupinambá, situada no continente, às margens da baía de São Marcos.

${ }^{4}$ Maranhão - estado brasileiro localizado na parte ocidental da região nordeste - recebeu escravos dos portos africanos de Santiago, Bissau e Cacheu. O Maranhão é um dos mais importantes redutos da cultura daomeana nas Américas (LOPES, 2004). 
Mas esse sucesso econômico não perdurou muito, e, quando cai em decadência, Alcântara é abandonada pelos proprietários das grandes fazendas, igual ao que aconteceu com as terras ocupadas pelas ordens religiosas, também deixadas para trás. Essa situação de abandono proporcionou aos escravos a oportunidade de reconstruir sua história no solo maranhense. O desolamento de Alcântara, para Almeida (2006, p. 71), revela uma situação peculiar, "posto que vastas extensões territoriais ficaram praticamente dois séculos sem uma presença efetiva de "senhores" e grandes proprietários e sem maiores pressões sobre a terra, que não fossem tentativas pontuais de aforamento". Passam a se organizar como povoados, nos quais o modo de vida era embasado nas tradições desses povos e nos recursos físicos e materiais destes espaços geográficos. Essa conjuntura favoreceu a formação de territórios de resistência.

Como Almeida (2006, p. 48) assinala, nesse contexto, as "terras de preto", "terras de Santo" e "terras de pobreza" representam aparentemente diferentes construções de território em termos étnicos. Contudo, convergem "por intermédio de uma relação associativa abrangente, para um mesmo processo de territorialização étnica". Tal mapa histórico possibilita entender porque, em Alcântara, a memória dos remanescentes de quilombos ultrapassa os embates militares e fatos heroicos, mas evoca formas de viver e de produzir fundamentados no uso comum dos recursos naturais e na "reciprocidade positiva" entre as famílias de diferentes povoados.

\section{Quilombos: Terras de preto, terras de santo, terras da pobreza}

No cenário de casas-grandes demolidas e engenhos abandonados, constroem-se os territórios étnicos sociais. Negros e negras, sem donos nem obrigações escravistas, abrigam suas famílias em construções rústicas, formando pequenos povoados nos quais se consolidaram direitos étnicos nas diversas territorialidades, definidas conforme a origem. As consideradas terras de preto eram terras adquiridas por prestação de serviços escravos, ou compradas por escravos alforriados.

As terras de santo, segundo Almeida (2006), constituíam territorialidades deixadas pelas ordens religiosas (Carmelitas) aos antigos escravos, no início da segunda metade do século XVIII. Nelas, não se observava resistência por posses individuais, mas a construção de povoados unidos por relações comunitárias. Outro território, também habitado por ex-escravos, era identificado como terras da pobreza, originado de doações das fazendas falidas, fato instituído em cartório, num ato de doação do proprietário.

Dessa forma, os ex-escravos constroem sua identidade com as atividades agrícolas, no âmbito de territorialidades delimitadas solidamente, conforme a desintegração de cada fazenda, "seja de algodão ou de cana-de-açúcar, seja de sesmeiros ou de ordens religiosas" (ALMEIDA, 2006, p. 81). Ainda sobre essa questão, Anjos (2007) afirma que, no espaço construído e materializado com base em elementos de identidade e de pertencimento territorial, perpassa entre a população um elo decorrente da origem comum.

Cada comunidade de remanescentes de quilombos criou seu modo próprio de viver, uma cultura híbrida, misturada por hábitos e costumes da cultura de brancos e indígenas, pois os quilombos abrigavam, além de ex-escravos negros, indígenas e pessoas 
excluídas da sociedade. Acerca da forma de viver nos quilombos, Almeida (2006, p. 66) afirma que "estabeleciam-se em povoações, em alguns casos tinham relações com as pessoas dos povoados e em outros viviam exclusivamente da agricultura, isolados nas clareiras dos bosques e evadiam o contato com pessoas de fora".

Nos referidos territórios, aprendem a conservar e cultivar coletivamente valores culturais herdados de seus ancestrais e praticam, em liberdade, um estilo de vida decorrente de seus quase três séculos de existência (SARTI, 2012). Configuram uma identidade própria de uma cultura reinventada, que se fundamenta no sentimento de solidariedade e no desejo de liberdade.

Na geografia social de Alcântara do século XIX, após a conquista do espaço, consolidam-se os territórios de resistência quilombolas. Conforme Almeida (2006), em Alcântara, se expandem os quilombos, entre 1811 e 1837, sem nenhuma ação repressora contra eles. Desse modo, se processa a construção das identidades quilombolas, embora a Constituição do Brasil, entre 1824 e 1891, não contemplasse os descendentes de escravos africanos como sujeitos de direito, muitos "eram considerados propriedade e tratados como tal" (DAVIS, 2000, p. 32). Em 1850, com a proibição do tráfico de negros, os quilombos ficam livres da opressão e percebidos pela sociedade civil como local de vida "fraterna e livre, com laços de solidariedade e convivência resultante do esforço dos negros escravizados de resgatar sua sociedade livre" (MUNANGA; GOMES, 2006, p. 72). Dessa forma, a concepção de quilombos como local de esconderijo é desconstruída e reaparece no cenário como comunidades negras rurais.

Na Constituição Federal de 1891, reitera-se o direito à liberdade dos cidadãos brasileiros, mas a liberdade dos escravos é excluída pela oligarquia liberal e pela falta de mobilidade social (DAVIS, 2000). Contudo, somente em 1988, a situação ganha reforço constitucional, através do artigo no 68 do Ato das Disposições Constitucionais Transitórias da Constituição Federal, sob o enunciado: "Aos remanescentes das comunidades de quilombos que estejam ocupando suas terras é reconhecida a propriedade definitiva, devendo o Estado emitir-Ihes os títulos respectivos". Na prática, esta disposição não é cumprida em sua totalidade, porém permite maior mobilidade social aos ex-escravos, pois o termo remanescente de quilombo confere aos quilombos uma referência, um sentimento de pertencimento a um lugar específico (ALMEIDA, 2006).

Os territórios sociais fundamentados em relações de parentesco e no acesso a terras livres favorecem a consolidação de uma identidade autônoma, quilombola. Nesse sentido, o modo de vida nas comunidades quilombolas se constitui em torno de relações sociais definidas por critérios de parentesco, afinidade e vizinhança, que se fundamentam no princípio de solidariedade e reciprocidade, trocando produtos e serviços, tanto de objetos para pesca e roçado como de gêneros alimentícios, para suprir as necessidades, sejam elas das famílias ou da comunidade.

Assim, será observada a flexibilidade das fronteiras desses territórios de resistência, isto é, como eles se compõem e decompõem conforme as posições dos atores sociais no espaço, nas diversas esferas da vida social e cultural: religiosa, ambiental, econômica e política, a partir da comunidade quilombola Peru, situada atualmente dentro do território político jurídico Agrovila Peru. 


\section{Território étnico: ex-comunidade quilombola Peru Velho}

Os dados apresentados neste artigo, relativos à Comunidade Quilombola Peru Velho, assim chamada pelos ex-moradores dos povoados, que agora habitam a Agrovila Peru, são baseados na análise do discurso de ex-moradores da comunidade, quando relatam sua trajetória histórica. Segundo eles, a comunidade quilombola foi constituída nos tempos da colonização, possivelmente originária das terras de preto. Esta consideração deriva da observação do processo de territorialização vivenciado pelos quilombolas no ato do deslocamento; na ocasião, havia uma família proprietária das terras e várias que trabalhavam ali como foreiros.

Aludem ao território nativo, Comunidade Peru Velho, como um paraíso perdido, em relação ao qual manifestam identidade com um modo de vida estreitamente ligado à natureza. "Peru Velho era um lugar que não tinha paisagens, tudo era pantanal, tinha rio bonito, com tudo verde ao redor, não era arruado, não havia maldade com a floresta, nós plantávamos e colhíamos", lembra uma das entrevistadas. Em relação ao rio, cabe assinalar, conforme os relatos, que este tem um significado cultural importante no modo de vida, suas águas limpas são usadas para tomar banho, lavar utensílios domésticos e também para usufruir de momentos de lazer.

Na busca de suprir sua alimentação, praticavam, em forma de mutirões, a agricultura de subsistência e a criação de animais, isto é, as atividades econômicas eram realizadas de maneira coletiva. Essas atividades são sazonais, sejam agrícolas, pecuárias ou extrativistas, e caracterizam as formas de uso dos elementos da natureza. Observouse que os ciclos das atividades econômicas seguiam as estações do ano, assim, para a criação do gado, "no inverno buscavam o gado na praia, para não morrer com os raios, e, no verão, o deixavam no campo e o traziam para se alimentar com a mandioca", disse um dos informantes. Neste contexto comunitário, valorizavam as práticas de agricultura de subsistência, oposta à agricultura comercial.

Na territorialidade desses grupos, a ocupação da terra não é feita individualmente, predomina o uso comum (O'DWYER, 2010). As ideias de coletividade e de comunidade vão em direção contrária ao sistema de produção individual e comercial, identidade fortalecida por ações sociais coletivas. Todavia, tudo não é positivo, conforme os relatos, as comunidades de quilombo caracterizavam-se pela precariedade tecnológica e escassez de serviços médicos e educacionais, "Lá no Peru Velho, só tinha uma escola, que ficava longe, não tinha médicos", mas tinham instituições próprias de grande valor cultural, entre elas o clube, a Casa da Festa, e a Casa do Forno, para fazer farinha, e os grandes terreiros, onde se dançava o tambor de crioula.

Nas comunidades, havia a liberdade de culto, muito embora, devido à imposição da igreja católica no período da colonização, se observava um grande contingente de seguidores. Mas, mesmo com a vocação católica, as tradições religiosas afro eram respeitadas pelos moradores da comunidade.

\section{Território étnico social Comunidade Peru Velho no território jurídico Agrovila Peru}

Em conformidade com a identidade fortalecida no viver em comunidade, os 
quilombolas manifestam resistência ao modo de vida que lhes é imposto no território Agrovila Peru. Nas falas, mostram que, nesse território, eles carecem dos elementos materiais e recursos naturais necessários para o desenvolvimento da cultura nativa. Para compreender esta situação, o argumento de Giddens (1996, p. 114) é esclarecedor, quando disse que "um modo de vida que poderia ser bastante modesto em termos econômicos, mas que era autossuficiente e organizado por meio da tradição local, acaba se destruindo quando o projeto de desenvolvimento - represa, plantação ou fábrica - é introduzido". Projetos de desenvolvimento como o CLA ${ }^{5}$ afetam negativamente a integridade cultural.

Esse cenário de destruição cultural é provocado e sustentado pelos projetos hegemônicos que chegam às comunidades quilombolas do entorno de Alcântara-Ma. No século XX, final da década de 80, o modo de vida característico das comunidades quilombolas maranhenses, em "terras de negro", "terras de santo" e "terras da pobreza", é alterado à raiz pela implantação do projeto do CLA, momento em que o então presidente do Brasil (José Sarney) desapropriou das suas terras, de maneira compulsória, dez comunidades quilombolas (BRAGA, 2011). Desabitou 52 mil hectares de terras, ocupadas por estas comunidades há mais de um século, e as doou para o Ministério da Aeronáutica, justificando que o espaço habitado por estes quilombolas estava localizado em uma área geográfica privilegiada para lançamentos de foguetes, devido a sua "posição geográfica, condições climáticas estáveis, baixa densidade populacional, facilidades de acesso marítimo e aéreo, e próximo à linha do equador" (RAMOS, 2011, p. 18).

Os remanescentes de quilombos expressam uma percepção crítica sobre o tratamento recebido pelo Ministério da Aeronáutica, percebem que eles os veem como se não existissem enquanto sujeitos, como se fossem uma "coisa". Os moradores associam a ação do CLA, nesse contexto, a uma espécie de volta ao passado remoto, que intitulam "tempo da escravidão", "cativeiro" ou "antes dos brancos irem embora". São vítimas de interdições à pesca, à coleta e ao livre acesso às praias, caminhos e trilhas centenárias, na atualidade sob controle da base militar (ALMEIDA, 2006).

$\mathrm{Na}$ Agrovila, para onde foram deslocados, cada família recebeu um módulo rural de 17 hectares, para o cultivo da roça, e uma casa de alvenaria construída em $72 \mathrm{~m}^{2}$, em lotes de $1000 \mathrm{~m}^{2}$. No referente à distribuição das terras entre as famílias deslocadas, os quilombolas foram lesados pelo Decreto № 72.571, da Presidência da República, em 18 de abril de 1986, pois "reduziu o módulo rural de Alcântara de 35 para 15 hectares apenas na área relativa à base, permanecendo o restante do município com a fração mínima de parcelamento já instituída" (ALMEIDA, 2006, p. 81).

Em 1987, é implantada a Agrovila Peru, no município de Alcântara, para abrigar os remanescentes de quilombos de dez comunidades, fenômeno que provoca mudanças nas estruturas física e material, alterando as condições objetivas de vida desses atores sociais. O novo cenário leva a que a comunidade quilombola Peru Velho, foco de aten-

\footnotetext{
${ }^{5}$ CLA - Base Espacial de alta tecnologia, considerado o segundo maior centro de lançamentos de foguetes do país, desde o ano de 1982 como a segunda maior base de lançamentos de foguetes da Força Aérea brasileira, criado em 1989, se constitui como um local onde se fazem lançamentos de foguetes de vários tipos, privilegiado pela baixa latitude (proximidade do Equador), e onde se desenvolve o programa do VLS (Veículo Lançador de Satélites).
} 
ção neste trabalho, seja compelida a interagir em espaços de produção influenciados direta ou indiretamente pelo processo de globalização, pois, tal como assinala Santos (2012), com a ampliação do contexto e dos processos globais, qualquer local, por menor que seja e isolado que pareça, representa o mundo, cada localidade está interconectada existencialmente ao mundo.

Considera-se que a referida conexão entre fenômenos locais e globais, no âmbito de Alcântara, seja um dos fatores que estimulam a construção e reconstrução de territórios e identidades em comunidades tradicionais de remanescentes de quilombo, como Peru Velho, pois, uma vez construída a Agrovila, como resultado de interesses governamentais em projetos globais, os antigos moradores de comunidades de quilombo, na área decretada, vivenciam a separação de elementos identitários e a contraposição de um processo produtivo. O novo modo de vida leva à quebra da organização social das comunidades e de suas hierarquias enquanto territórios de parentesco. Instituemse regras e critérios de autoridade local diferentes, que colidem com princípios formadores das comunidades de quilombo (ALMEIDA 2006). Quer dizer, o território jurídico político Agrovila Peru, construído através da intervenção da aeronáutica, rompe com os princípios dos territórios de parentesco, que regiam a organização social. Nesse processo, os antigos membros das comunidades constroem e desconstroem identidades, para marcar fronteiras com outros territórios sociais e políticos, que resultam da relação com novos atores sociais e novos valores.

Como alguns cientistas sociais têm notado (CASTELLS, 1999; HALL, 2000; GIDDENS, 1996), apesar de a globalização ser um processo hegemônico, não configura, necessariamente, a homogeneização cultural. Os atores sociais, individuais ou coletivos, são inseridos no processo de globalização e assumem posturas diferenciadas, que se refletem na assimilação ou negação dos valores culturais globalizadores e na construção ou reconstrução de identidades.

Seguindo o pensamento de Stuart Hall (2000), os elementos de identidade que anteriormente localizavam os indivíduos sociais, como etnia, raça e nacionalidade, entre outros, deixam de existir. Se antes os elementos de identidade sustentavam-se no seguimento a uma tradição cultural, fundamentada em regras, costumes e valores próprios, no âmbito dos quais primavam os interesses coletivos, na contemporaneidade, essas velhas identidades que serviam de estabilizadores do mundo social entram em declínio, fazendo surgir novas identidades e a fragmentação de outras. Em outras palavras, as identidades que compunham os territórios sociais e que asseguravam a conformidade subjetiva com as necessidades objetivas da cultura entram em colapso, como resultado de mudanças estruturais e institucionais.

As pessoas vivenciam a crise de identidade resultante de um processo mais amplo de mudança, que desloca as estruturas e processos centrais das sociedades modernas. É o que ocorre com os antigos moradores das comunidades de quilombo, hoje assentados na Agrovila Peru. Suas identidades pessoais mudam, perdem o sentido de si, dá-se um deslocamento ou descentralização dos indivíduos, tanto de seu lugar no mundo social e no cultural quanto de si mesmos.

Ainda interpretando a realidade da Agrovila Peru à luz dos argumentos de Hall (2000), observa-se que a identidade unificada que os sujeitos tinham se fragmenta; ago- 
ra, na Agrovila, são múltiplas as identidades dos sujeitos, algumas contraditórias entre si. O processo de identificação, através do qual se projetavam as identidades culturais, tornou-se provisório, variável e problemático. Os moradores da Agrovila representam o sujeito pós-moderno, sem identidade fixa, essencial ou permanente. Neste contexto, o "eu real" do sujeito é modificado e formado em diálogo com mundos culturais exteriores.

As referidas teorias contribuem para entender como é vivenciado socialmente o processo de territorialização, decorrente do impacto da globalização, a partir da análise das identidades dos ex-moradores da Comunidade Peru Velho, na Agrovila Peru. Nesse contexto, observa-se a coexistência de vários territórios, que se diferenciam pelos elementos identitários que os definem. Embora em alguns contextos ainda se observem marcas de identidade com um passado comum, a origem quilombola, percebe-se que ao longo das décadas, na Agrovila, os moradores têm construindo novas identidades, resultantes das mudanças sociais, políticas e econômicas vivenciadas no novo modo de vida. Contudo, as novas identidades não excluem as identidades sociológicas das quais trata Hall (2000), pois, no mesmo território social, convivem as identidades marcadas pela herança cultural e as identidades construídas à raiz da estrutura física e social imposta pelo governo federal às comunidades. Assim, os moradores não se libertam completamente do apoio estável que a tradição tem Ihes proporcionado ao longo da história como quilombolas. Em algumas situações, assumem uma postura de resistência através da preservação dos traços de sua africanidade.

Nesta mesma linha de ideias, outro autor que aborda os reflexos do capitalismo contemporâneo em formas culturais e na organização do trabalho com base nas identidades, é Castells (1999). De sua ótica, as identidades se constroem como resistência à pretensa homogeneização do capitalismo globalizado, e sua construção pode ser o germe de mudanças socioculturais. Este autor classifica as manifestações identitárias em tipos, marcados pela história da comunidade, as instituições, os aparelhos de poder e as crenças religiosas. Como a construção social da identidade é marcada por relações de poder, o autor propõe três formas e origens da construção de identidades.

A identidade legitimadora é introduzida pelas instituições dominantes da sociedade, no intuito de expandir e racionalizar sua dominação em relação aos atores sociais. Dá origem a um conjunto de organizações e instituições, bem como a uma série de atores sociais, estruturados e organizados, que, embora às vezes de modo conflitante, reproduzem a identidade que racionaliza as fontes de dominação estrutural. São as organizações, as instituições e os atores sociais em que se sustenta a estrutura na Agrovila Peru, para produzir e reproduzir a identidade dominadora.

Outra categoria de Identidade proposta por Castells é a de resistência, gerada por atores sociais que ocupam posições desvalorizadas ou discriminadas. Estas identidades são formas de resistência coletiva das comunidades diante de uma opressão, partem dos materiais culturais a que têm acesso, para definir sua posição na sociedade. Sindicatos, movimentos sociais de quilombos: a Associação das Comunidades Negras Rurais Quilombolas do Maranhão (ACONERUQ), Movimento das Mulheres Trabalhadoras Rurais (MOMTRA) e o Movimento dos Atingidos são alguns exemplos dessa construção de identidades coletivas de resistência contra o poder institucional da Aeronáutica sobre a Agrovila Peru. Ainda de modo muito expressivo, envolvem-se em associações que reivin- 
dicam melhorias para a agrovila, como a Base Espacial de Alcântara (MABE).

E o terceiro tipo de identidade, no marco das relações de poder, é a identidade de projeto, que produz sujeitos. Sujeitos que não são indivíduos, mas o ator social coletivo, pelo qual a experiência do indivíduo adquire um significado holístico. A identidade se constrói como um projeto de vida diferente, talvez com base numa identidade oprimida, porém se expandindo no sentido de transformação da sociedade.

No entanto, como Castells (1999) assinala, essas identidades se completam entre si, identidades de resistência podem ser também identidades de projeto. Identidades legitimadoras transformam-se em identidades de resistência.

As observações, no território político jurídico Agrovila Peru acerca das identidades, revelam que, neste cenário, surgem novos elementos de identidade que os moradores precisam incorporar, para dar continuidade àquela vida com recursos que antes não tinham, mas que são essenciais no novo estilo de vida. Só que, em contrapartida, como ressalta Giddens (1996, p. 97), "as influências globalizadoras tendem a esvaziar os contextos locais de ação [...] as principais mudanças ocorrem na própria urdidura da vida cotidiana, afetando até mesmo a constituição de nossas identidades pessoais".

Como forma de resistência a essas influências globalizadoras, os quilombolas se apoiam em identidades coletivas, que priorizam formas de organização tradicional, em torno das quais se constrói a sociabilidade, que se fundamenta em relações de parentesco, de compadrio e de vizinhança, expressas no partilhar coletivo dos acontecimentos ordinários, atividades no dia a dia, bem como dos extraordinários, nascimentos, casamentos e mortes. Para este fortalecimento identitário, a comunidade deslocada Peru Velho, no ato do deslocamento, exigiu que todas as famílias de sua comunidade fossem alocadas em uma mesma rua, esta distribuição espacial permitiria dar continuidade às relações pessoais, reforçadas por laços de parentesco. Isto é, a proximidade física evitaria a fragilização das relações sociais, constituídas por vínculos de sangue e de casamento.

Em termos cartográficos, na Agrovila, há quatro ruas principais, cuja distribuição corresponde a territórios sociais delimitados com base na história de vida em comum dessas comunidades. Essa distribuição não distanciou, ou criou fronteiras entre as comunidades que habitam a Agrovila, haja vista que as atividades coletivas, como a produção da farinha, a pesca, as festas religiosas e as uniões matrimoniais acontecem envolvendo moradores de comunidades diversas. Todos utilizam os espaços públicos oferecidos na Agrovila, como escolas, poços artesianos, campo de futebol, cemitério, casa de farinha, lavanderia, igrejas, sem nenhuma discriminação. Foi detectado que as comunidades que possuíam menor número de famílias no ato do deslocamento, ao chegarem na Agrovila, preferiram, mesmo com poucas famílias, ocupar ruas vicinais e designar o nome de sua comunidade para aquela rua, como forma de manter, na memória coletiva, o nome de sua comunidade de origem.

No cotidiano da Comunidade Quilombola Peru, não há registro de atitudes de marginalização em relação aos costumes e tradições de outras comunidades. As singularidades de cada comunidade, como festas que honram os santos padroeiros e outros rituais religiosos, foram relegadas ao passado e incorporaram elementos sociais advindos com a evolução tecnológica. No entanto, as comunidades que possuíam maior número de famílias no ato do deslocamento e que permanecem ainda morando na Agrovila 
mantêm algumas de suas tradições, como é o caso de Peru Velho, que realiza todos os anos o festejo de Nossa Senhora da Conceição, organizado por pessoas das diferentes comunidades da Agrovila.

Destaca-se também, como legado cultural na comunidade Peru Velho, o papel social dos idosos. Enquanto atores sociais bastante respeitados, devido a suas experiências de vida e conhecimentos em relação à natureza e aos seres humanos, os idosos são consultados, para resolver problemas de ordem pessoal, física, profissional e emocional. Contudo, como Almeida (2006) aponta, a autoridade dos antigos declina. Não são mais os encarregados de terra vinculada a aforamentos, nem zelam pelos bens de santos e santas nem disciplinam o uso de madeiras de lei, as reservas de mata e os recursos hídricos, como o faziam antigamente.

Sarti (2012) assinala que, nas comunidades deslocadas, as pessoas redefinem, no cotidiano, a identidade cultural intimamente centrada no valor da ancestralidade e da religiosidade. Ainda que timidamente, preservam certos valores e crenças religiosas ligadas à cultura negra, os quais denotam manifestações de resistência perante os efeitos da globalização. Contudo, apesar dos quilombolas apresentarem manifestações de resistência às mudanças culturais globais, percebe-se que, no decorrer do tempo, acabam incorporando-as.

A cultura dos quilombolas é ameaçada pela força da globalização, quando são compulsoriamente deslocados para uma Agrovila construída pelas autoridades governamentais, concebida conforme um padrão cultural residencial alheio ao seu e fundamentado na ideologia dominante. Nesse sentido, seguindo Santos (2007, p. 36), "os construtores do espaço não se desembaraçam da ideologia dominante quando concebem uma casa, uma estrada, um bairro, uma cidade".

Em alguns contextos, percebem-se manifestações de resistência dos quilombolas frente ao poder da aeronáutica e do governo federal. Um deles é nas moradias: cada família buscou organizá-las de acordo com suas tradições, escolhendo a cor para pintar a fachada das casas, as plantas do jardim e as do pomar, bem como as mudanças internas e externas nas casas, a despeito da proibição do Ministério da Aeronáutica que, após vinte anos, não entregou o título definitivo das casas para os quilombolas, descumprindo o acordo estabelecido por ambas as partes envolvidas nesse processo de deslocamento.

A falta de documentação do título das casas tem gerado um conflito que se arrasta desde o período do deslocamento, na década de 80, no século XX: sem o documento, sentem-se lesados. A casa, que antes fazia parte da identidade dos moradores, pensada e construída por eles, agora são espaços emprestados. Esta situação constrange-os e provoca em alguns moradores revolta visível, ao se caminhar pelas ruas da Agrovila, na deterioração e no abandono das casas. De acordo com Almeida (2006, p. 81), "para os quilombolas o viver nas agrovilas não garante os recursos e autonomia necessários para a manutenção da família com casa e terras para plantio. Sentem-se humilhados de ter que pedir autorização para o CLA para construir novas casas". Estão sujeitos às decisões da autoridade administrativa para construir. A Aeronáutica dificulta "a construção de casa para os filhos; mais de 33 famílias, vivendo na agrovila e sem casas para morar; ameaças constantes de remover as casas que teriam sido construídas na agrovila sem autorização da Aeronáutica" (ALMEIDA, 2006, p. 82). 
A dominação do território físico-social que compõe a Agrovila, por parte do governo federal e do Ministério da Aeronáutica via CLA, é exercida em diversas dimensões da vida cotidiana dos moradores, permitindo ou proibindo o acesso a espaços que antes eram de uso comum. A maneira de responder à coibição do uso do espaço comum é desenvolvendo atividades produtivas de caráter individual, incorporando o individualismo característico do capitalismo globalizado, que provoca a fragmentação nas relações sociais. Na agrovila, muitos habitantes já não retiram da terra seu sustento, alegam que é grande a distância atual das casas para as glebas de terra onde é permitido o plantio da roça, e que estas terras são impróprias para o cultivo de mandioca, "a gravidade da situação é percebida pela queda da produção de mandioca que, entre 1985 e 1996, caiu 40\%" (ALMEIDA, 2006, p. 55). Todas as restrições a que os quilombolas são submetidos limitam o acesso a recursos necessários para a subsistência. Contudo, alguns ainda resistem a abandonar suas roças nas terras que, por lei, agora pertencem ao Ministério da Aeronáutica. Apesar da distância, argumentam que são terras mais produtivas. A pesca marítima é outra atividade de subsistência nas comunidades de quilombos que ficou prejudicada pela longa distância do mar. Os moradores, quando teimam em pescar na antiga comunidade, precisam adquirir um crachá no CLA, e, mesmo com restrições, mantêm a pesca como prática de subsistência.

No marco das referidas regras de uso comum dos recursos, combinam formas de apropriação privada com apropriação pública, como estratégia de sobrevivência há dois séculos. A exclusão e desconhecimento da significação dessas práticas pode se traduzir como estratégica. Deslocar compulsoriamente comunidades que se dedicam à pesca marítima e a coleta de frutos de mar e das praias para o interior do continente é destruir seu modo de vida e impedir a reprodução social (ALMEIDA, 2006).

Perante as dificuldades, um percentual alto de moradores da Agrovila Peru procura, para resolver sua situação econômica, os benefícios das políticas públicas através de programas assistencialistas, como Bolsa Família e Brasil Carinhoso, programas dos quais obtém recursos para comprar arroz, feijão e farinha, alimentos que antes eles mesmos produziam. "Um dos resultados mais visíveis é que nas agrovilas tem-se o enfraquecimento dos grupos familiares que permanecem nas agrovilas, que passam a gravitar principalmente em torno dos aposentados" (ALMEIDA, 2006, p. 82).

Assim, a situação dos moradores da Agrovila Peru revela como eles, enquanto sujeitos, constroem identidades diversas, às vezes, contraditórias entre si. Nesse processo de construção de identidades com novos territórios sociais aos que se inserem, distanciam-se progressivamente da identidade étnica. São imersos num mundo de regras incompatíveis com o modo de vida anterior ao deslocamento. Nele, perdem a liberdade de ir e vir pelos espaços de produção comunitários, nos quais se sustentava o modo de vida social e econômico. Este fenômeno, à luz do argumento de Guattari (1990, p. 12), depara com o mesmo paradoxo: "o desenvolvimento contínuo de novos meios técnicocientíficos [...] e a incapacidade das forças sociais organizadas e das formações subjetivas constituídas de se apropriar desses meios para torná-los operativos".

O modo de vida dos quilombos esbarra com o modelo de vida social capitalista, desenvolvimentista, no qual impera a dialética social do mercado, e o domínio tecnológico penetra diversos setores sociais, que tendem à homogeneização, mas, como assinala 
Santos (2012), cada sociedade e cada cultura incorpora esses elementos tecnológicos em acordo com os valores culturais. Percebe-se que o avanço tecnológico traz benefícios, mas, em alguns contextos, desestabiliza e modifica a cultura, mudanças que se refletem na construção de múltiplas identidades e no deslocamento permanente dos elementos de identidade como formas de viver na sociedade heterogênea.

\section{Referências}

ALMEIDA, Alfredo Wagner Berno. Os quilombolas e a base de lançamento de foguetes de Alcântara: laudo antropológico. Brasília: MMA, 2006.

ANJOS, R. S. A dos. Territórios étnicos: o espaço dos quilombos no Brasil. In: SANTOS, R. E. dos (Org.). Diversidade, espaço e relações sociais: o negro da Geografia do Brasil. Belo Horizonte: Autêntica, 2007. p. 115 - 136.

BRAGA, Yara Maria Rosendo de Oliveira. Território étnico: conflitos territoriais em Alcântara - Maranhão. Dissertação (Mestrado em Planejamento Urbano Regional) Universidade do Vale da Paraíba, São José dos Campos, 2011.

CASTELLS, Manuel. O poder da identidade. São Paulo: Paz e Terra, 1999.

DAVIS, Darien J. Afro-brasileiros hoje. São Paulo: Selo Negro, 2000.

GUATTARI, Félix. As três ecologias. São Paulo: Papirus, 1990.

GIDDENS, Anthony. Para além da esquerda e da direita. O futuro da política radical. São Paulo: Universidade Estadual Paulista, 1996.

HALL, Stuart. A identidade cultural na pós-modernidade. 4. ed. Rio de Janeiro: Instituto Geia, 2000.

MUNANGA, Kabengele; GOMES, Nilma Lino. O negro no Brasil de hoje. São Paulo: Global, 2006.

LOPES, Nei. Enciclopédia Brasileira da Diáspora Africana. São Paulo: Selo Negro, 2004.

O'DWYER, Eliane Cantarino. Terras de quilombo no brasil: direitos territoriais em construção. In: ALMEIDA, Alfredo Wagner Berno de. Cadernos de debates Nova Cartografia Social: Territórios quilombolas e conflitos. Manaus: Projeto Nova Cartografia Social da Amazônia/UEA Edições, 2010. p. 43-44

RAMOS, Albani; DUARTE, Sebastião Moreira. Alcântara: alma e história. São Luís: Instituto Geia, 2011.

SANTOS, Milton. Por uma outra globalização: do pensamento único à consciência universal. 22. ed. Rio de Janeiro: Record, 2012.

SANTOS, R. E. dos. (Org.). Diversidade, espaço e relações sociais: o negro na Geografia do Brasil. Belo Horizonte: Autêntica, 2007.

SARTI, Ingrid. Alcântara, espaço e terra. Uma população em oblívio. 2012. Disponível em: <http://www.achegas.net/numero/dezenove/ingrid_sarti_19.htm>. Acesso em:

4 abr. 2014. 